\title{
The Problem of Nonexistence: Truthmaking or Semantics? Critical Notice of The Objects of Thought, by Tim Crane
}

\author{
Lee Walters \\ University of Southampton \\ BIBLID [0873-626X (2015) 41; pp. 231-245]
}

Tim Crane's The Objects of Thought is, I think, a much needed corrective to standard ways that analytic philosophers think about nonexistence. It starts from our common sense thought and talk, and tries to carve out a position that can defend this starting point in the face of criticism. It is well-written, a pleasure to read, and largely clear. I would recommend it to anyone interested in the problems of nonexistence. In $\S 1$ I sketch Crane's central ideas about the nonexistent, before turning to themes that I would like to have heard more about. In $\S 2$, I distinguish two problems of nonexistence, showing that whilst Crane solves one, he does not address the other. Although Crane did not seek to address both problems, I think we should recognize that there is this residual problem of nonexistence remaining. Next (§3), I argue that whilst Crane is correct to think that a negative free logic has to be rejected if we construe it as making a claim about grammatical subject-predicate sentences, we might be able to salvage it if we recognise a class of logical predicates. But whether this is possible or not, depends on the solution to the unaddressed problem of nonexistence. In the final two sections I briefly raise a concern about Crane's view of quantification, before making a suggestion about how his view might be employed in addressing Geach's problem of intentional identity.

\section{Crane's approach}

Some of the things we think about exist, like Buda Castle, but some

Disputatio, Vol. VII, No. 41, November 2015

Received: 19/11/2015 
of the things we think about, like Hogwarts, do not. Hence there are truths about the nonexistent, such as Lee is thinking about Hogwarts. And yet the world does not contain more than what exists. Tim Crane's task is to defend and reconcile these apparently conflicting common sense claims.

But wait, you might think. Do we really think about the nonexistent? Surely, if I am thinking about something, there must really be something for my thought to be about. Thinking about is, so the objection goes, what Crane calls a 'real' or 'substantial' relation, and so entails its relata. Certainly this suggestion is not without merit, and even those friendly to providing accounts of empty names, such as Mark Sainsbury (2005: 237-238), have denied that we do think about the nonexistent. Still, Crane is correct that our thoughts are characterized in certain ways, even when there is nothing in reality that we are thinking of, and it seems that the English word 'about' is as good a way as any to capture this phenomena. So, just as there can be drawings and sculptures of Peter Pan, there can be thoughts about him too. Crane does, however, recognize that there is a real relation in area, and he reserves the word 'reference' for this relation: one can think or talk about Peter Pan, but one cannot refer to him.

I am thinking about Peter Pan; Peter Pan does not exist; therefore, some of the things I am thinking about do not exist. So as well as thinking and talking about the nonexistent, we can also quantify "over" them. It seems to be part of the data that some of the things we think about do not exist. Moreover, for Crane, so-called existential readings of 'there is' sentences are semantically equivalent to their corresponding 'some' sentences. This is because 'there' is a semantically vacuous term, present simply because syntax requires it. So, there are things we think about that do not exist. But this is not an ontological claim, since, for Crane, nonexistents are no part of reality in any sense. Rather, it "is simply another way of saying that we can genuinely think about things that don't exist” (2003: 5).

Crane's view is, then, something of a hybrid. It resembles a positive free logic in that it allows for true seemingly simple sentences containing non-referring terms, but it is Meinongian in that its unrestricted quantifiers range "over" nonexistents: in free logics traditionally conceived, the quantifiers range over only existents, and traditional Meinongian pictures allow for reference to nonexistents. 
In this way, Crane's picture is an improvement on these rival views. It seems to be a fact about English that there are true generalizations about nonexistents, and I myself cannot make sense of a picture on which we refer to, as opposed to talk about, the nonexistent, since there are not really any.

Crane, following standard usage, reserves the symbols $\exists$ and $\forall$ for quantifying over the existents. Because Crane allows for meaningful empty names, these quantifiers are subject to a free logic, and so the rules for existential generalization and universal instantiation need to be restricted to cases in which $\exists x(x=a)$. But as we have seen, Crane does not think the English word 'some' corresponds to $\exists$. Rather than 'some' expressing the existential quantifier, Crane could have followed others in saying that it expresses a particular quantifier, $\Sigma$, and that 'all' has a corresponding reading, $\Pi$, that ranges "over" both nonexistents and existents. These quantifiers behave classically with unrestricted particular generalization and universal instantiation, and so allow for the move from 'I am thinking about Peter Pan' to ' $\Sigma \mathrm{x}$ Lee is thinking about $\mathrm{x}$ '.

Despite sharing some features with other forms of neo-Meinongianism, Crane's view differs sharply in that he rejects any form of characterization principle along the following lines

CP: Nonexistents are the way they are characterized as being by the appropriate myth, theory, fiction, etc.

Moreover, he differs from some positive free logicians in that he denies that nonexistents can have any ordinary properties such as being a horse, being a detective, or being located in space. For Crane, these are existence entailing properties, and so cannot be had by nonexistents.

So what truths concerning the nonexistent does Crane allow for? For Crane these fall in to three categories. First, there are negative existential claims such as Hogwarts does not exist. Second, there are representation-dependent truths, examples include being thought about, being famous, and being a fictional character. Third, Crane allows for the truth of trivial identity statements, such as Peter Pan is Peter Pan (although how to spell-out what a trivial identity statement is is not itself trivial (2013: 165)). Crane's task is to provide an account of how these statements about the nonexistent can be true 
given that the nonexistent are no part of reality.

Crane offers a "metaphysical reduction" of these claims about the nonexistent, providing truth makers for these truths, in his noncommittal, not theoretically-loaded sense of this phrase. But unlike neo-Meinongians, he wants to do this without metaphysical extravagance, and so eschews appeals to Meinongian object theory with its reliance on impossible worlds, the distinction between nuclear and extra-nuclear properties, or between encoding and instantiating. So how exactly does Crane account for the truths above?

First, nonexistence claims are made true simply in virtue of the fact that the world does not contain nonexistents. As Crane puts it, "the falsity of 'Vulcan exists' is ensured by the fact that reality ... does not contain Vulcan" (2013: 119); there is no truth maker for 'Vulcan exists'. So given that 'Vulcan exists' is false, its negation is true. And as Crane notes (2013: 73), this negation is expressed by 'Vulcan does not exist'.

Second, representation-dependent truths are true, as the name suggests, in virtue of the existence of some representation, whether this is a story, a theory, or an episode of thinking. So, for instance, 'Vulcan was a planet postulated by Le Verrier' is true iff there was an event where Le Verrier represented Vulcan as a planet in certain way (2013: 135).

Third, self-identity claims follow from the "logical truth that for all $\mathrm{x}, \mathrm{x}=\mathrm{x}$ " (2013: 165), where this must be understood as $\Pi \mathrm{x} \mathrm{x}=\mathrm{x}$, if it is to yield, say, that Vulcan=Vulcan by universal instantiation. But why think $\Pi \mathrm{x} x=\mathrm{x}$ is a logical truth? Well, in classical systems it follows from the rule for introducing identity, $a=a$, by universal introduction. But whether $\mathrm{a}=\mathrm{a}$ is a logical truth is precisely what is at issue, so Crane cannot appeal to this to justify his claim. So I think that Crane has not provided any independent reason for us to accept that nonexistents are in fact self-identical. Moreover, there does not seem to be anything in the world to ground these self-identity claims; 'Vulcan=Vulcan' has no truth maker as Crane admits (2013: 163). I think it would be simpler and more in keeping with Crane's project to deny that these claims are in fact true.

Apart from the three types of truth about the nonexistent that Crane explicitly discusses, we should also count as true negative claims made with any existence entailing properties, not just negative 
existentials: if it is true that Vulcan does not exist, given the absence of Vulcan, then it is also true than Vulcan is not a planet, since being a planet is existence entailing. Finally, Crane might want to consider which modal claims concerning nonexistents are true. Perhaps Vulcan could not have existed? If so, perhaps some modal claims are also existence entailing, and so can be subsumed by the previous point.

Despite what many philosophers have said about quantification and empty names, Crane's general picture above seems dead right to me. It is, I think, on the basis of theoretical considerations that have not been adequately justified, that some resist this intuitive picture. So Crane is to be applauded for spelling-out this common sense picture of the nonexistent, and rejecting philosophical orthodoxy. And yet, some will not be completely satisfied with Crane's solution.

\section{The problems of nonexistence}

Crane states the problem of nonexistence as follows: "if truth is supervenient on being, then how can one truly say of something that is not - something that has no being - that it is a certain way? How can such a claim be true?" (2003: 20). It is not entirely clear what the tension is supposed to be here. After all, does anyone think that there are possible worlds where the existence facts are the same, but the truths about nonexistents differ? Supervenience is not really the issue here, I think. For Crane, the issue is better put in terms of truth making. The problem of nonexistence, as Crane thinks of it, is that given that nonexistents are not a part of reality, what are the truth makers for statements about them? As Crane himself puts it, "Given that when something is true, it is reality that makes it so, we are obliged to ask: what in reality makes these claims about the non-existent true?" (2013: 118). As we saw above, Crane sets out to answer this question, and his answer seems on the right lines to me.

But is this enough? Crane describes his reductionism as providing an explanation of the truth of statements about the nonexistent without giving the meaning of those statements. We might, however, also want an account of the meaning of such statements. The residual problem of the nonexistent, unaddressed by Crane, is how to provide systematic truth conditions for claims about the nonexistent, without appealing to reference to nonexistents. 
Now Crane can be forgiven for not engaging in this no doubt difficult, and largely technical semantic project. It is fine for there to be a division of philosophical labour, and Crane's positive picture was well worth setting-out as a much needed alternative to more extravagant approaches. Still, there is this residual problem, and until this problem has been solved, Crane's extravagant opponents, at least, will view his approach with suspicion.

A related worry comes from asking how Crane thinks we should decide ontological questions? He says that what people are in fact committed to is a matter of what they believe in, rather than what they quantify over. Fair enough. But we can ask what ought they, objectively, believe in. How do we settle that question? Crane does not think that there is an informative formal criterion of which object-language sentences are ontologically committing (see below). So perhaps he thinks ontological commitment is determined by which entities are appealed to in the metalanguage when giving the semantics of the object-language. But Crane, as we have seen, does not provide such a semantics. His opponents may suspect that once he does provide a semantics he will find himself faced with the same extravagant choices he criticizes.

As well as Crane's truth maker conception of the problem of nonexistence, then, there is another problem that we can characterize with the following inconsistent triad (I do not say these two problems exhaust the problems of nonexistence):

(1) There are true subject-predicate sentences about nonexistents.

(2) If a subject-predicate sentence ' $a$ is F' is true, then ' $a$ ' refers.

(3) At least one subject term in a subject-predicate sentence about nonexistents lacks a referent.

Crane, effectively, takes (3) to be a constraint on the solution, and I agree. He also takes (1) to be constitutive of the problem, so, he rejects (2). But (2) follows from the simple view of truth

SVT: A predicative sentence, ' $a$ is $F$ ' is true iff the object denoted by ' $a$ ' has the property ascribed by ' $F$ '. 
And so as Crane rejects (2), he also rejects SVT. But he does not provide a systematic alternative to SVT, which leaves open the questions just raised. In the next section, I sketch some thoughts on Crane's account of properties and predicates, and a different way of thinking that is nonetheless consonant with his whole approach.

\section{Properties and predicates}

Crane claims that there are true subject-predicate sentences about the nonexistent. Moreover, he says that these sentences are true because the nonexistent the sentence is about has the property ascribed by the predicate. Does this, then, not allow him to answer the challenge faced above? As Crane notes, on his view "The truth-conditions for a claim of the form ' $a$ is $F$ ' is that it is true just in case $a$ has the property $F$. We can state the truth-conditions in this form, in the same way, whether or not ' $a$ ' refers to anything" (2013: 58).

Here it might look like Crane is going some way to providing the systematic theory I asked for. This impression is, I think, illusory (not that Crane claims otherwise) since the properties that nonexistents have are, for Crane, "pleonastic", the result of the grammatical transformations from ' $a$ is F', to 'there is a property that $a$ has, namely Fness'. As a result, to say that ' $a$ is $F$ ' is true just in case $a$ has the property $F$ is not to provide an explanation of why ' $a$ is $F$ ' is true. They are simply two ways of saying the same thing.

Now one way of holding on to SVT, but allowing for truths about the nonexistent, is to adopt a negative free logic that supplements SVT with

NFL: If ' $a$ ' does not refer, then any subject-predicate sentence, ' $a$ is $F$ ' is false.

With NFL we can account for the falsity of all of the existence entailing claims concerning nonexistents, and thus for the truth of their negations, including negative existentials. But although NFL is consistent with their being truths about nonexistents, it does not allow for true subject-predicate claims about the nonexistent, and so it resolves the residual problem of nonexistence by rejecting (1). Although Crane would be happy to accept this approach for a range of sentences, he rejects it in its full generality, since he thinks that 
it cannot provide a satisfactory account of representation-dependent truths. In brief, this is because Crane thinks that not all of these truths can be accounted for by employing intensional operators taking subject-predicate sentences within their scope. Rather, Crane thinks that there are true representation-dependent, subject-predicate sentences concerning nonexistents, and so NFL has to be rejected.

Crane thinks that there are true predications concerning nonexistents because he follows Dummett (1973: 37-38) in saying that a predicate is what results when we remove one or more referring expressions from a sentence. There are at least three worries that we might raise for this conception. First, one might want to exclude certain complex sentences from this method of predicate formation, otherwise we can have what appear to be incompatible predicates true of the same object. For instance, Frege's puzzle might give rise to the predicates 'Lee believes that $\mathrm{x}$ is $\mathrm{F}$ ' and 'Lee does not believe that $\mathrm{x}$ is F' (as opposed to 'Lee believes $\mathrm{x}$ is not F'). Second, even ignoring complex sentences, this method might be objected to because it allows for a predicate 'Professor $\mathrm{x}$ was an expert on Tarot' to be generated by removing 'Dummett' from 'Professor Dummett was an expert on tarot'. But it does not make any sense to predicate this of an object, as can be seen by completing the predicate with some other phrase that picks out Dummett, such as 'the Wykeham Professor of Logic in 1985'. This problem could be avoided, however, by placing a suitable restriction on what counts as a referring term in the relevant sense. But even leaving all this to one side, there is a third problem which is brought out by considering Quine's (1960: 153) example of

(4) Giorgione was so-called because of his size.

By the Dummett method of predicate formation, this yields the predicate

(5) x was so-called because of his size.

But it is odd to say that (5) is a predicate. First, it does not allow for substitution of co-referring terms, even when we concern ourselves with de re readings. For it is not true that 
(6) Barbarelli is such that he was so-called because of his size.

Relatedly, one cannot quantify into this predicate since neither

(7) $\exists x$ ( $x$ was so-called because of his size)

(8) $\quad \sum_{\mathrm{x}}(\mathrm{x}$ was so-called because of his size $)$

make sense. But it seems to me that the notion of a predicate is tied as much to quantification as it is to combining with singular terms.

The real predicate involved in (4) is more perspicuously given by

(9) x was called 'Giorgione' because of his size

and (9) is not subject to the problems above.

Moreover, (4) puts pressure on the notion of a pleonastic property, since we cannot move from (4) to

(10) There is a property Giorgione has, namely so-called because of his sizeness.

What this shows, then, is that it is not as harmless as Crane suggests to think of true claims concerning nonexistents as true subject-predicate claims where the nonexistent has a pleonastic property corresponding to the predicate. The point of this is to bring out that as well as Dummett's grammatical notion, we also have the separate notion of a logical predicate. And it is the logical notion, I suggest, that is important to the assessment of NFL. Crane rejects NFL because

The mere idea of a sentence free of truth-functional operators, and of 'intensional' operators ... is clear enough, but [examples like 'Vulcan was a planet postulated by Le Verrier'] show that these restrictions do not on their own determine a kind of expression which always determines a falsehood when combined with a non-referring term. There does not seem to be a syntactic or formal criterion of simplicity [for a predicate in NFL's sense] (2013: 55).

Now I think the negative free logician has more formal resources than Crane considers. For one thing, the passive versions of representation-dependent truths often sound much worse than the active forms: compare 'Le Verrier is thinking about Vulcan' with 'Vulcan is being thought about by Le Verrier'. But not all do, and it is not clear 
that there is surface-form syntactic criterion of a logical predicate. Still, it might be correct that there is an interesting class of expressions, logical predicates, that when combined with an empty name, always produce a falsehood, but that this class cannot be read-off surface structure. The only way to discover if this is true is by doing the semantics and discovering the logical forms of the problematic sentences. If there is a class of logical predicates that combine with empty names to produce false sentences, then perhaps the thought behind NFL is vindicated. Further, these logical forms would correspond to the existence entailing properties, and so we would have an explanation of which properties are existence entailing.

What about the representation-dependent truths? If these are not logical predications, what are they? It seems to me that what (many of) these truths are doing is not ascribing a property to, or predicating something of a nonexistent, in some intuitive sense that has not been made precise. Rather, they are characterizing representations as Peter Pan-sculptures, Vulcan-theories, Holmes-stories, Pegasusthoughts, etc. Whether, ultimately, this approach can be sustained to defend NFL is not clear, but it is only by investigating the logical forms of sentences that we can find out. In any case, this approach, which takes characterizing as primitive (see Forbes 2006) seems to fit well with Crane's (2013: 90) proposal to take intentionality as primitive.

Regardless of the logical forms of claims about the nonexistent, Crane is right to reject NFL as a claim about (surface) syntactically simple sentences. But by investigating why it is false read as such, by seeking to provide a systematic semantics for the nonexistent, we open up the possibility of drawing some worthwhile logical distinctions between sentences that are genuinely ascribing properties of their subjects and those that are not, and between claims that entail the existence of their subjects, and those that do not. Consequently, we might be able to ward off the suspicions of some of Crane's opponents, and maintain the possibility of doing ontology in something like the Fregean tradition. All of this goes beyond what Crane sought to do in his book. And as I have said, I think that his general picture and metaphysical reduction must be correct. Still, I think some investigation of these issues would have been interesting. 


\section{Quantification}

Crane, as we saw allows for quantification "over" nonexistents. I have repeatedly used scare quotes because it was not entirely clear to me what Crane's account amounts to exactly. Crane says that he wants to keep "the basic ideas of the logic of quantification intact" (2013: 31). So what, then, does it mean to quantify "over" nonexistents for Crane?

It is to have non-existent objects of thought in the universe of discourse, where ... to have an object of thought in the universe of discourse is to have it among the things relevant to what we are talking about ... These things can be 'values' of the variables bound by the quantifiers, just in the sense that things can be true or false of the objects of thought. So, when evaluating 'some biblical characters did not exist' we look for something in the domain (biblical characters) of which we can predicate non-existence. And lo! We find one: Abraham. Abraham is then a value of the variable (2013: 40).

Note how Crane himself uses scare quotes for 'values'. If Crane wants to say that we can quantify over nonexistents in the way in which standard logic quantifiers over a domain of existents, then I would like to have seen more detail about assignment functions, satisfaction, and the like to help me fully understand what was going on. But it seems to me that Crane does not need to go down this route, since, at other points, his account of quantification does not appear to amount to quantifying over nonexistents. Rather, it seems to be a device of generalizing into certain syntactic positions:

After all, if we can use a name to talk of something which does not exist, then the quantifier 'some' is just a generalization from the use of a name (2013: 16).

quantified sentences [such as] ... 'Some characters in the Bible did not exist' - are best understood as generalizations from sentences that predicate something of their subjects (2013: 119).

I would have liked to have heard more about whether this kind of syntactic generalization was what Crane had in mind, and also how his approach compares with others who have adopted such approaches. 


\section{De re thought}

After setting out his metaphysical picture, Crane (2013, chapter 6) turns to the problem of thinking about specific nonexistents. There is too much in this chapter to cover, so I shall just focus on his discussion of de re thought. Here, as is standard, Crane construes the de re/de dicto distinction syntactically, so that quantifying into a belief report, say, counts as de re.

After noting that singular thoughts can be attributed de dicto, Crane considers whether singular thought entails a de re attribution. Crane notes that whereas on the orthodox conception, this is true, since ' $\mathrm{S}$ believes that ... a ...' entails ' $\exists \mathrm{x}$ ( $\mathrm{S}$ believes ... of $\mathrm{x}$ )', no such entailment is forthcoming on Crane's account, since we can believe things about the nonexistent. Rather than take this as counting against singular thought about the nonexistent, Crane instead rejects the idea that singular thought entails de re attribution.

Now clearly Crane is correct that beliefs about the nonexistent do not license existential generalization. And so if existential generalization is required for the de re, then singular thought about the nonexistent does not entail a de re reading. But why think that existential quantification is required? The syntactic construal of the de re does not mention existential quantification. Moreover, given that Crane employs something like a particular quantifier that quantifies "over" nonexistents, he is free to acknowledge de re attributions of belief concerning nonexistents. For example, $\Sigma_{\mathrm{x}}$ such that Crane believes $\mathrm{x}$ does not exist.

Two options present themselves. First, Crane could accept that singular thought, even about the nonexistent, does entail a de re attribution, albeit one in terms of the particular, rather than the existential, quantifier. Second, he could reject the syntactic criterion of the de re given above, in favour of a relational construal of the de re. This seems to fit better with Crane's way of thinking since he glosses 'de re' at several points as 'relational', where I take him to mean substantially relational. If this is right, then there is no purely syntactic characterization of the de re for Crane, just as there is no syntactic construal of the ontologically committing claims.

But having pulled apart the syntactic and relational construals of 'de re', it seems as if Crane is in a position to provide an irrealist 
construal of the problematic Geach sentence concerning intentional identity:

(11) Hob thinks a witch blighted Bob's mare, and Nob wonders whether she (the same witch) killed Cob's sow.

It has been thought that (11) cries out for a syntactically de re reading. But on the standard assumption that quantification is ontologically committing, such a reading commits to there being something in reality that Hob and Nob's mental states are about. But such a consequence is unwelcome. However, once we sever the link between quantification and ontological commitment, as Crane does, we can give a syntactically de re reading without these unwanted consequences along the lines of the following:

(12) $\sum \mathrm{x}$ (x is a witch) such that Hob thinks that (x is a witch and) $\mathrm{x}$ blighted Bob's mare, and $\Sigma$ y such that Nob wonders whether $\mathrm{y}$ (a witch) killed Cob's sow, and $\mathrm{x} \approx \mathrm{y}$,

where the material in parentheses can be included or not depending on how exactly we read (11). Two comments. First, ' $\mathrm{x} \approx \mathrm{y}$ ' means $\mathrm{x}$ is the same as $\mathrm{y}$, to be discussed below. Second, as Nathan Salmon (2015) notes, it seems plausible to suggest that 'witch' has a reading on which it can be truly predicated of mythical witches, and also a reading which means something like 'is a mythical witch or a real witch' (compare 'gun' and 'poet', in 'is that gun real or fake' and 'how many poets are there living or buried in Budapest?' (cf. Partee 2010). If so, Crane can take the occurrence of 'witch' outside the scope of the propositional attitudes as not committing to real witches.

But what of ' $\mathrm{x} \approx \mathrm{y}$ '? Aside from the trivial identity statements discussed above, Crane does not allow for true identity statements concerning nonexistents, so $\mathrm{x} \approx \mathrm{y}$ cannot be treated as $\mathrm{x}=\mathrm{y}$. Crane (2013: 163-164) suggests that we cash out ' $\mathrm{x} \approx \mathrm{y}$ ' in terms of the resemblance of representations: Mercury and Hermes are not literally identical, but we can say that they are "the same", by virtue of the similarity of the representations of $\mathrm{x}$ and $\mathrm{y}$. For some purposes this might be right, but I think that often our sameness talk reflects more than qualitative similarity. If I say that you and I have the same car, what this would ordinarily mean is that we have the same type 
of car, such as a VW Golf. But being a VW Golf is not (merely) a matter of resemblance, for causal links are important too-if your car just happens to look like a VW Golf then it is not in fact a VW Golf. How however we cash out this talk of types, we cannot employ the same treatment in the case of nonexistents: nonexistents do not fall under any causally-individuated type, since they don't exist. Nevertheless, I think that to account for some of our sameness talk concerning the nonexistent, we must appeal to causation, since it seems that whether we count fictional characters as being the same (from an irrealist perspective) depends on whether the uses of the names we use to speak of them are related. If so, it might be helpful for Crane to appeal to Sainsbury's (2005, chapter 3) name-using practices, and then to ground (some) sameness talk in terms of causally related name-using practices along the lines of Salis (2013). But as long as Crane has a satisfactory account of ' $\mathrm{x} \approx \mathrm{y}$ ', it seems as if he might be well-placed to offer an account of (11). ${ }^{1}$

Lee Walters Department of Philosophy University of Southampton Avenue Campus Southampton, S017 1BF l.walters@soton.ac.uk

\section{References}

Crane, T. 2013. The Objects of Thought. Oxford: Oxford University Press. Dummett, M. 1981. Frege Philosophy of Language. Second Edition. London: Duckworth.

Forbes, G. 2006. Attitude Problems. Oxford: Clarendon Press.

Partee, B. 2010. Privative Adjectives: subsective plus coercion. In Presuppositions and Discourse: Essays offered to Hans Kamp, ed. by Rainer Bäuerle, Uwe Reyle and Thomas Ede Zimmermann. Bingley, UK: Emerald Group Publishing, 273-285.

Quine, W.V.O. 1960. Word and Object. Cambridge, MA: MIT Press.

Sainsbury, R.M. 2005. Reference without Referents. Oxford: Oxford University Press.

${ }^{1}$ Thanks to the Institute of Advanced Study at the Central European University for a Junior Fellowship during which I wrote this piece. 
Salis, F. 2013. Fictional Names and the Problem of Intersubjective Identification. Dialectica 67: 283-301.

Salmon, N. 2015. The Philosopher's Stone and Other Mythical Objects. In Fictional Objects, ed. by Stuart Brock and Anthony Everett. Oxford: Oxford University Press, 114-128. 
